\title{
LA INFLUENCIA DEL TRIBUNAL EUROPEO DE DERECHOS HUMANOS EN EL EJERCICIO DE LA FUNCIÓN CONSULTIVA DE LA CORTE INTERAMERICANA DE DERECHOS HUMANOS
}

\begin{abstract}
Anamari GARRO
RESUMEN: Luego de dar un marco conceptual, se analizan las opiniones consultivas cronológicamente para determinar la existencia, el grado y las materias de la influencia del TEDH. Desde la primera etapa de la Corte IDH, el sistema europeo fue punto de referencia, pero de 19 opiniones consultivas sólo ocho invocan sentencias del TEDH. Éstas se refieren a diversas materias: el principio no discriminación, la libertad de expresión, los criterios hermenéuti$\cos$, los derechos del niño y temas conexos, la naturaleza subsidiaria de los sistemas internacionales de protección de los derechos humanos, la eficacia del CEDH en las relaciones interindividuales, etcétera. Ciertamente el número de sentencias invocadas aumentó en las últimas opiniones, pero acudir a la jurisprudencia europea ha dependido más de la materia sobre la que versa la opinión que de la época en que ésta fue dictada, la integración del órgano o la intervención de los amici curiae. Al incorporarse por vía de autoridad a las opiniones consultivas de la Corte IDH, la jurisprudencia del TEDH se convierte en una destacada fuente material que configura formalmente los ordenamientos jurídicos americanos. Se está en presen-

ABSTRACT: After giving a conceptual framework, the consultive opinions are analyzed chronologically for determining the existence, the level and the subjects of the influence of the HREC. Since the first phase of the HRIC, the European system was the reference point, but of 19 consultive opinions, only eight call on sentences of the HREC. Those refer to different subjects; no-discrimination principle, expression liberty, hermeneutic criteria, children rights and connected topics, the subsidiary nature of the international systems of protection of human rights, the efficiency of the HREC in the inter individual relationships, etcetera. Certainly the number of invoked sentences raised in the last opinions, but the coming up to the European jurisprudence has depended more in the subject in with it was dictated, the integration of the organ or the intervention of the amici curiae. By incorporating via consultive opinions authority of the HRIC, the HREC jurisprudence evolves into an emphasized source of material that formally forms the American judicial orders. We are in presence of a judicial globalization phenomenon.
\end{abstract} cia de un fenómeno de globalización jurídica.

Palabras clave: Corte Interamericana de Derechos Humanos, función consultiva, influencia del Tribunal Europeo de Derechos Humanos.

Fecha de recepción: 16 de junio de 2008.

Fecha de dictamen: 18 de septiembre de 2008.
Descriptors: Interamerican Court of Human Rights, Consultive Function, Influence of the European Court of Human Rights. 


\section{INTRODUCCIÓN}

El derecho constitucional contemporáneo no puede prescindir del estudio de las fuentes del derecho internacional de los derechos humanos porque hoy inciden en la configuración de los ordenamientos jurídicos internos o son parte de éstos. Dentro de esas fuentes, en el continente americano tiene especial relieve la jurisprudencia de la Corte Interamericana de Derechos Humanos (Corte IDH o Corte). El análisis que aquí se intenta realizar tiene un objeto material y otro formal muy específicos: ${ }^{1}$ las opiniones consultivas desde la óptica de la influencia que en ellas ha tenido el Tribunal Europeo de Derechos Humanos (TEDH).

El estudio está circunscrito a la función consultiva de la Corte IDH por dos razones: una eminentemente práctica - el universo de opiniones consultivas es mucho menor que el de los casos - ; ${ }^{2}$ y otra de índole teórica - el interesante diseño de la función consultiva: su objeto, la legitimación activa y los efectos de esas resoluciones-.

En primer término, se ofrecerá el marco conceptual que desarrollará los aspectos que faciliten la mejor compresión del tema que aquí interesa. Por tanto, se dejarán de lado el examen sobre las diferencias entre la competencia contenciosa y la consultiva, y lo relativo al procedimiento.

1 No se pretende aquí confrontar ambos sistemas regionales, sino solamente medir la influencia del TEDH en su órgano homólogo interamericano. Para un extenso y profundo análisis comparativo de esos sistemas, véase Úbeda de Torres, Amaya, Estudio comparado de los sistemas europeo e interamericano de protección de los derechos humanos, Madrid, Reus, 2007, passim, que a su vez recoge un listado de varios estudios comparativos de ambos sistemas, cfr. ibidem, pp. 671-673. Ni siquiera se intenta aquí comparar ambos órganos judiciales. Para eso, véase Londoño Lázaro, María Carmelina, "Las cortes Interamericana y Europea de Derechos Humanos en perspectiva comparada", International Law-Revista Colombiana de Derecho Internacional, Bogotá, núm. 5, junio de 2005, passim. Por otro lado, hace algunos años se publicó un trabajo cuyo objeto de estudio era mucho más amplio e incluía el análisis sobre la recepción de la jurisprudencia del TEDH en los pronunciamientos de la Corte IDH: véase, Boeglin, N., Analyse des systèmes européen et interaméricain de pretection des droits de l'homme: Etude de l'impact de l'expérience européenne sur le système interaméricain, Mémoire dans le cadre du Lauréat du Conseil de l'Europe 1992-1993, Estrasburgo, COE, 1993, citado por Úbeda de Torres, Amaya, op. cit., supra, p. 352.

2 Se han resuelto hasta el 15 de agosto de 2008, cierre de la XXXV Periodo Extraordinario de Sesiones, 186 pronunciamientos en el ejercicio de su competencia contenciosa, y 19 opiniones consultivas. Toda la jurisprudencia de la Corte se encuentra en el sitio www.corteidh.or.cr. 
Posteriormente, se dará un panorama general y sobre todo descriptivo de las opiniones consultivas, que irán desfilando en orden cronológico. Se podrá constatar cuáles y en relación a qué temas han apoyado sus argumentaciones en sentencias del TEDH.

Por último, se harán unas breves anotaciones sobre los factores que podrían haber incidido en la recepción de la jurisprudencia europea: la etapa en que fue dictado el pronunciamiento de la Corte, la integración de este órgano - asunto naturalmente unido al anterior-, la influencia de los amici curiae y el tema sobre el que versa la opinión misma.

Es preciso subrayar que la perspectiva desde la que se analizan las opiniones consultivas es ésta: la influencia de la jurisprudencia del TEDH que en ellas se advierte, y no la importancia que cada opinión tiene en sí misma en el ámbito americano. ${ }^{3}$ Además, no se hace un estudio de los pronunciamientos sino una referencia al contexto de la invocación, al lugar que ésta ocupa en el iter del razonamiento, tanto si trata de la opinión de la Corte como de los votos particulares.

Respecto de la jurisprudencia europea conviene tener presente que ésta proviene del ejercicio de la función contenciosa del TEDH, pues hasta la fecha ese órgano no ha ejercido su función consultiva. ${ }^{4}$ Precisamente, esto marca una de las diferencias más notables - respecto de la competencia - entre ambos órganos regionales de protección de los derechos humanos. ${ }^{5}$ Finalmente, es oportuno precisar que lo que aquí se

3 Para conocer una síntesis de las líneas jurisprudenciales más relevantes vertidas en las opiniones consultivas anteriores a Corte IDH. El derecho a la información sobre la asistencia consular en el marco de las garantías del debido proceso legal. Opinión consultiva OC-16/99 del 1 de octubre de 1999. Serie A núm. 16, inclusive, véase Pacheco Gómez, Máximo, "La competencia consultiva de la Corte Interamericana de Derechos Humanos", Memoria del Seminario: El sistema interamericano de protección de los derechos humanos en el umbral del silgo XXI, San José, Corte IDH, 2003, t. I, passim. Un estudio similar, pero respecto de las primeras 14 opiniones consultivas, puede encontrarse en Albanese, Susana, Derechos humanos. Estudio de casos y opiniones consultivas, s. 1. i. [Buenos Aires], Editorial de Belgrano, 1997, t. I, pp. 51-69.

4 Se recoge una explicación sucinta pero completa de las características de esta competencia en Ruiz Miguel, Carlos, "La función consultiva en el sistema interamericano de derechos humanos, ¿crisálida de una jurisdicción supra-constitucional?", Liber amicorum: Héctor Fix-Zamudio, San José, Corte IDH, 1998, vol. II, pp. 1355-1356. Sobre las razones por las que no ha sido ejercida, cfr. ibidem, p. 1362.

5 Cfr. Buergenthal, Thomas, "Las convenciones Europea y Americana: algunas similitudes y diferencias", Seminario regional referente a la Convención Americana sobre 
llama jurisprudencia del TEDH, no necesariamente constituye una línea jurisprudencial consolidada: la determinación de cuándo sí lo es, excede las pretensiones de estas líneas. Aquí se utiliza la palabra jurisprudencia como sinónimo de sentencia. ${ }^{6}$

\section{MARCO CONCEPTUAL: EL EJERCICIO DE LA FUNCIÓN CONSULTIVA DE LA CORTE IDH}

\section{Contexto normativo}

El sistema interamericano de derechos humanos es un entretejido de normas e instituciones. ${ }^{7}$ Dentro de las primeras, destaca la Convención

Derechos Humanos, organizado por la Comisión Interamericana de Abogados y la Facultad de Derecho de la Universidad de Costa Rica, Washington D. C., Comisión Interamericana de Derechos Humanos-Secretaría General de la OEA, 1980, p. 184. Además, la propia Corte ha mencionado estas diferencias en diversas opiniones: Corte IDH, "Otros tratados". Objeto de la función consultiva de la Corte (artículo 64 Convención Americana sobre Derechos Humanos). Opinión consultiva OC-1/82 del 24 de septiembre de 1982. Serie A núm. 1, párrafo 16, y Corte IDH. Restricciones a la pena de muerte (artículos 4.2 y 4.4 Convención Americana sobre Derechos Humanos). Opinión consultiva OC-3/83 del 8 de septiembre de 1983. Serie A núm. 3, párrafo 43. Pero ha de tenerse presente que la CADH siguió "la técnica y el método de la Convención Europea, dejando de lado el modelo de la competencia consultiva de la CIJ y se limit[ó] a modificar el régimen del modelo, ampliando la competencia consultiva de la Corte Interamericana", Gros Espiell, Héctor, Estudios sobre derechos humanos, Madrid, IIDH-Civitas, 1988, pp. 233 y 237. Incluso la CADH copia la palabra "concernientes", que ha sido clave en la determinación de la extensión de la competencia consultiva ratione materiae, cfr. OC-1/82, supra, passim.

6 Además se dice sentencia del TEDH o sentencia europea, tanto para referirse a la que proviene del órgano judicial europeo existente antes del Protocolo 11 del Convenio Europeo para la protección de los Derechos Humanos y las Libertades Fundamentales (CEDH), como al creado por este protocolo. Infra, nota 78.

7 Sobre el desarrollo histórico de éste, entre otros, véase García Bauer, Carlos, "La observancia de los derechos humanos y la estructuración del sistema internacional de protección en el ámbito americano", Seminario regional, cit., nota 5, pp. 19-29. También véase una síntesis en Ruiz Miguel, Carlos, op. cit., nota 4, pp. 1356-1357. Sobre su diseño y funcionamiento, véase, Faúndez Ledesma, Héctor, El sistema interamericano de protección de los derechos humanos. Aspectos institucionales y procesales, 3a. ed., San José, Instituto Interamericano de Derechos Humanos, 2004, passim. Y para todos los temas señalados en esta nota, pero haciendo hincapié en la competencia contenciosa, véase García Ramírez, Sergio, "La protección de derechos y libertades en el sistema jurisdic- 
Americana de Derechos Humanos (CADH o Pacto de San José) que en su capítulo 8o. crea la Corte IDH, otorgándole dos tipos de competencia: la contenciosa y la consultiva. ${ }^{8}$ La función consultiva está contemplada en el artículo 64 de la $\mathrm{CADH}$, que dice:

1. Los Estados miembros de la Organización podrán consultar a la Corte acerca de la interpretación de esta Convención o de otros tratados concernientes a la protección de los derechos humanos en los Estados Americanos. Asimismo, podrán consultarla, en lo que les compete, los órganos enumerados en el capítulo X de la Carta de la Organización de los Estados Americanos, reformada por el Protocolo de Buenos Aires.

2. La Corte, a solicitud de un Estado miembro de la Organización, podrá darle opiniones acerca de la compatibilidad entre cualquiera de sus leyes internas y los mencionados instrumentos internacionales.

Como se puede apreciar, este artículo define la competencia ratione materiae, es decir, el objeto del ejercicio de la función consultiva; y la competencia ratione personae, que es como el anverso de la legitimación activa para solicitar la consulta. Los alcances de esta norma han sido definidos por la propia Corte en diversas opiniones consultivas, como seguidamente se verá.

\section{A. Competencia ratione materiae $y$ ratione personae}

Respecto de la competencia ratione materiae, ha sido clave determinar cuáles son "los otros tratados concernientes a la protección de los derechos humanos en los Estados Americanos" (artículo 64, párrafo 10. y, por renvío, el artículo 64, párrafo 2o.), y qué se entiende por "leyes internas" (artículo 64, párrafo 20.).

Sobre la primera frase, la Corte ha dicho que su competencia consultiva

puede ejercerse, en general, sobre toda disposición, concerniente a la protección de los derechos humanos, de cualquier tratado internacional aplicable en

cional interamericano. El amparo interamericano", en Fix-Zamudio, Héctor y Ferrer Mac-Gregor, Eduardo (eds.), El derecho de amparo en el mundo, México, UNAM-Porúa-Konrad Adenauer Stiftung, 2006, passim.

8 Sobre el ámbito de esta competencia, los requisitos formales de la consulta, la admisibilidad de ésta, el procedimiento y los efectos de las opiniones consultivas, véase Faúndez Ledesma, Héctor, op. cit., nota anterior, pp. 949-994. 
los Estados americanos, con independencia de que sea bilateral o multilateral, de cuál sea su objeto principal o de que sean o puedan ser partes del mismo Estados ajenos al sistema interamericano. ${ }^{9}$

De manera que el objeto sobre el que recae esta competencia es amplísimo: lo relevante es que sean tratados en que esté directamente implicada la protección de los derechos humanos en un Estado americano miembro de la OEA. ${ }^{10}$ En un momento posterior, la propia Corte señaló que en su función consultiva era competente también para interpretar las reservas a la CADH, ${ }^{11}$ y la Declaración Americana de Derechos y Deberes del Hombre (DADDH) — cuando, en el marco y dentro de los límites de su competencia, ello sea necesario para interpretar la Carta de la OEA y la $\mathrm{CADH}-.^{12}$

En relación con lo dicho en el artículo 64, párrafo $20 .{ }^{13}$ este órgano judicial ha precisado que "siempre que un convenio internacional se refiera a "leyes internas", sin calificar en forma alguna esa expresión o sin que de su contexto resulte un sentido más restringido, la referencia es para toda la legislación nacional y todas las normas jurídicas de cualquier naturaleza, incluyendo disposiciones constitucionales". ${ }^{14}$ Además, estas normas pueden estar en proceso de formación. ${ }^{15}$

9 Corte IDH, "Otros tratados". Objeto de la función consultiva de la Corte, cit., nota 5 , nota 5, parte resolutiva, primer punto.

10 Ibidem, párrafos 19, 21, 34, 37, 48.

11 Corte IDH, El efecto de las reservas sobre la entrada en vigencia de la Convención Americana sobre Derechos Humanos. Opinión Consultiva OC-2/82 del 24 de septiembre de 1982. Serie A núm. 2, párrafo 12 y Corte IDH, Restricciones a la pena de muerte, cit., nota 5, párrafo 45 .

12 Corte IDH, Interpretación de la Declaración Americana de los Derechos y Deberes del Hombre en el marco del artículo 64 de la Convención Americana sobre Derechos Humanos. Opinión consultiva OC-10/89 del 14 de julio de 1989. Serie A núm. 10, párrafos 36,43 y 44 .

13 Este párrafo marca una diferencia entre la competencia consultiva de la Corte IDH respecto de la del TEDH, pues éste carece de esta posibilidad, pero lo establecido en ese artículo 64 es de origen europeo. Cfr. Gros Espiell, Héctor, Estudios sobre derechos humanos, cit., nota 5, p. 234.

14 Corte IDH, Propuesta de modificación a la Constitución Política de Costa Rica relacionada con la naturalización. Opinión consultiva OC-4/84 del 19 de enero de 1984. Serie A núm. 4, párrafo 14.

15 Cfr. Corte IDH, Propuesta de modificación a la Constitución Política de Costa Rica relacionada con la naturalización, cit., nota anterior, párrafo 16 y Corte IDH, Com- 
Con gran agudeza se ha observado que las tres solicitudes de opinión que han tenido como base el artículo 64, párrafo 2o. de la $\mathrm{CADH}$, dos han sido con carácter preventivo ${ }^{16} \mathrm{y}$, se podría añadir, que en las tres se ha pedido específicamente medir la compatibilidad del derecho interno con la CADH y no con otro tratado. Quizá por eso algunos han llamado a esta vía "enjuiciamiento sobre la convencionalidad", ${ }^{17}$ pero evidentemente es más que eso, porque dicha norma pone como punto de referencia - sobre el que debe darse la compatibilidad - a "los mencionados instrumentos internacionales" (artículo 64, párrafo 2o.), que son la $\mathrm{CADH}$ y/o los otros tratados concernientes a la protección de los derechos humanos en los Estados americanos (artículo 64, párrafo 1o.). Por lo demás, la Corte desde el primer momento dejó claro este punto, al decir que "no se ve ninguna razón para que no pueda solicitar consultas sobre la compatibilidad entre cualquiera de sus leyes internas y tratados concernientes a la protección de los derechos humanos, que hayan sido adoptados fuera del marco del sistema interamericano". ${ }^{18}$ En fin, que esta competencia va más allá de un simple "enjuiciamiento sobre la convencionalidad". Sólo se podría hablar de tal enjuiciamiento si en la solicitud de opinión se pidiera calibrar la compatibilidad del derecho interno, específica y exclusivamente, con el Pacto de San José; pero la competencia atribuida en el artículo 64, párrafo 2o. de la $\mathrm{CADH}$ es bastante más amplia.

La competencia ratione personae está determinada por el fin de la consulta: si se trata del artículo 64, párrafo 1o., pueden solicitarla - en lo que les compete - los órganos de OEA mencionados en ese párrafo y todos los Estados americanos - incluidos los que no son Estado parte de la

patibilidad de un proyecto de ley con el artículo 8.2.h de la Convención Americana sobre Derechos Humanos. Opinión consultiva OC-12/91 del 6 de diciembre de 1991. Serie A núm. 12, párrafo 22. Sobre el particular, se ha dicho que "esta competencia consultiva de la Corte... puede aparecer como crisálida de una futura jurisdicción supra-constitucional", Ruiz Miguel, Carlos, op. cit., nota 4, p. 1360.

16 Ruiz Miguel, Carlos, op. cit., nota 4, pp. 1360 y 1361.

17 Ibidem, p. 1361. En el mismo sentido, $c f r$. Instituto Interamericano de Derechos Humanos, Guía metodológica para el desarrollo de un curso sobre el Sistema Interamericano de Derechos Humanos, San José, IIDH-McCormick Tribune Foundation, 2002, p. 50. Ahí es denominada "especie de consulta de "convencionalidad»".

18 Corte IDH, "Otros tratados". Objeto de la función consultiva de la Corte, cit., nota 5 , párrafo 39 . 
CADH-; y si se trata del artículo 64, párrafo 2o., lo serán estos últimos y sólo en relación con su propio ordenamiento jurídico.

\section{B. Efectos de las opiniones consultivas}

Excede la finalidad del presente estudio tanto dilucidar el problema sobre cuál es la fuerza vinculante de las opiniones consultivas como determinar si la naturaleza de las resoluciones de la Corte IDH es diversa cuando la base jurisdiccional ha sido un párrafo u otro del artículo 64 de la CADH. Sin embargo, conviene al menos señalar someramente los términos de estos problemas, por la relevancia que tienen en sí mismos y para el tema que está por analizarse. Como lo que aquí se intentará es determinar la influencia de la jurisprudencia del TEDH - que en el contexto americano tiene el carácter de fuente material- en las opiniones consultivas de la Corte IDH, naturalmente, la importancia de tal influencia está en relación directa con la eficacia de esa fuente formal.

Ha sido la propia Corte la que se ha pronunciado sobre eso, y se podría decir que no contra legem pero sí sine legem, pues el artículo 64 de la $\mathrm{CADH}$ no dice nada respecto de los efectos de las resoluciones en el ejercicio de su función consultiva. La Corte ha dicho que ésta es una "función asesora", 19 "un método judicial alterno de carácter consultivo, destinado a ayudar a los Estados y órganos a cumplir y a aplicar tratados en materia de derechos humanos, sin someterlos al formalismo y al sistema de sanciones que caracteriza el proceso contencioso". ${ }^{20}$ Además, ha

19 Corte IDH, "Otros tratados". Objeto de la función consultiva de la Corte, cit., nota 5, párrafo 14. Era, por lo demás, la tónica de la doctrina de la época: $v$. gr., se afirmaba que "cuando la Corte ejercita su competencia consultiva, emite una opinión, que tiene el valor de un dictamen o parecer y cuya fuerza resulta sólo del respeto debido a la autoridad moral y científica de la Corte". Dunshee de Arranches, Carlos Alberto, "La Corte Interamericana de Derechos Humanos", Seminario regional, cit., nota 5, p. 120. La cursiva es del original. No obstante, se ha señalado que esa función asesora le corresponde a la Comisión, según se desprende del artículo 41, inciso e) de la CADH. Cfr. Faúndez Ledesma, Héctor, op. cit., nota 7, p. 992.

20 Corte IDH, Restricciones a la pena de muerte, cit., nota 5, párrafo 43. En el mismo sentido: Corte IDH, Propuesta de modificación a la Constitución Política de Costa Rica relacionada con la naturalización, cit., nota 14, párrafo 19; Corte IDH, La colegiación obligatoria de periodistas (artículos 13 y 29 Convención Americana sobre Derechos Humanos). Opinión consultiva OC-5/85 del 13 de noviembre de 1985. Serie A núm. 5, párrafo 21; Corte IDH, Compatibilidad de un proyecto de ley con el artículo 8.2.h de la 
señalado que "las opiniones consultivas de la Corte, como las de otros tribunales internacionales, por su propia naturaleza, no tienen el mismo efecto vinculante que se reconoce para sus sentencias en materia contenciosa". ${ }^{21}$ Es más, ha manifestado que "si esto es así, menos razones existen para sacar argumentos de los eventuales efectos que pudieran tener frente a Estados que ni siquiera habrían participado en el procedimiento consultivo". ${ }^{22}$ No obstante, en las últimas resoluciones ha ido mutando un poco su posición, al afirmar que "aun cuando la opinión consultiva de la Corte no tiene el carácter vinculante de una sentencia en un caso contencioso, tiene, en cambio, efectos jurídicos innegables". ${ }^{23}$ Pero, incluso en esa ocasión, indicó que las resoluciones emanadas en el ejercicio de la función consultiva no son vinculantes: al menos eso es lo que desprende de la frase, interpretada a contrario sensu, recogida líneas después, que dice: "Debe advertirse que, aun en casos contenciosos sometidos ante la Corte en los cuales el Estado demandado puede ser objeto de decisiones vinculantes, la facultad discrecional de retener el conocimiento de un caso reside en la Corte". ${ }^{24}$

$\mathrm{Al}$ referirse a los efectos, la Corte no ha distinguido entre los dos supuestos contemplados en los respectivos párrafos del artículo 64 de la

Convención Americana sobre Derechos Humanos, cit., nota 15, párrafo 20; Corte IDH, El derecho a la información sobre la asistencia consular en el marco de las garantías del debido proceso legal, cit., nota 3, párrafo 64; Corte IDH, Condición jurídica y derechos humanos del niño. Opinión consultiva OC-17/02 del 28 de agosto de 2002. Serie A núm. 17, párrafo 34; Corte IDH, Condición jurídica y derechos de los migrantes indocumentados. Opinión consultiva OC-18/03 del 17 de septiembre de 2003. Serie A núm. 18, párrafo 64. Esta tesis, por lo demás, es respaldada por la doctrina de esa época: $v$. gr. Buergenthal, Thomas, "The Inter-American Court of Human Rights", The American Journal of International Law, vol. 76, núm. 2, 1982, pp. 244 y ss., citado por Faúndez Ledesma, Héctor, op. cit., nota 7, p. 990.

21 Corte IDH, "Otros tratados". Objeto de la función consultiva de la Corte, cit., nota 5, párrafo 51. En el mismo sentido, cfr. Corte IDH, Restricciones a la pena de muerte, cit., nota 5, párrafo 32; Corte IDH, La colegiación obligatoria de periodistas, cit., nota 20, párrafo 22 .

22 Corte IDH, "Otros tratados". Objeto de la función consultiva de la Corte, cit., nota 5 , párrafo 51 .

23 Corte IDH, Informes de la Comisión Interamericana de Derechos Humanos (artículo 51 Convención Americana sobre Derechos Humanos). Opinión consultiva OC15/97 del 14 de noviembre de 1997. Serie A núm. 15, párrafo 26.

24 Ibidem, párrafo 27. La cursiva no es del original. 
CADH. ${ }^{25}$ Por eso, entrelazado con el tema del carácter vinculante de esas decisiones, se ha señalado que la denominación que la propia Corte y su Reglamento hacen de esas resoluciones - al llamarlas opiniones consultivas indistintamente - no es acorde con la letra del Pacto de San José. ${ }^{26}$ Tal tesis afirma que en el primer párrafo del artículo mencionado se establece la competencia de interpretar autorizadamente esa Convención y los otros tratados concernientes a la protección de los derechos humanos en los Estados americanos. De manera que en este caso la Corte emite un verdadero dictamen de carácter vinculante, no sólo para el Estado que ha solicitado, sino para todo Estado parte del Pacto. En cambio, en el segundo párrafo de esa disposición, se faculta a la Corte para dar una opinión consultiva, vinculante de modo directo sólo para el Estado parte que ha sometido el asunto. ${ }^{27}$

En la discusión doctrinal sobre la conveniencia de esa idéntica denominación, paradójicamente, las tesis contrapuestas coinciden en querer reconocer un efecto vinculante a las resoluciones de la Corte en el ejercicio de su función consultiva. ${ }^{28}$ En efecto, aún sin hacer distinción entre

25 Por el contrario, sí los ha distinguido respecto del procedimiento. Cfr. Corte IDH, Propuesta de modificación a la Constitución Política de Costa Rica relacionada con la naturalización, cit., nota 14, párrafo 17 .

26 Para una crítica de los argumentos de Faúndez Ledesma, véase, Nikken, Pedro, "La función consultiva de la Corte Interamericana de Derechos Humanos", Memoria del Seminario: El sistema interamericano de protección de los derechos humanos en el umbral del silgo XXI, San José, Corte IDH, 2003, t. I, pp. 171-179. Sobre el valor jurídico de las opiniones consultivas, véase también, Piza Rocafort, Rodolfo, "La jurisdicción consultiva de la Corte Interamericana y el valor jurídico de sus opiniones", Acta Académica, núm. 3, San José, Universidad Autónoma de Centroamérica, octubre de 1988, passim, citado por Gros Espiell, Héctor. La Convención Americana de Derechos Humanos y la Convención Europea de Derechos Humanos. Análisis comparativo, Santiago, Editorial Jurídica de Chile, 1991, p. 173; y Rodríguez Rescia, Víctor Manuel, "Eficacia de la jurisprudencia de la Corte Interamericana de Derechos Humanos", en Nieto Navía, Rafael (ed.), La Corte y el sistema interamericano de derechos humanos, San José, Instituto Interamericano de Derechos Humanos, 1994, pp. 470-473.

27 Esto último en razón del artículo 33 de este instrumento y del principio de buena fe recogido en el artículo 26 de la Convención de Viena sobre el Derecho de los Tratados. Sobre el particular, cfr. Faúndez Ledesma, Héctor, op. cit., nota 7, pp. 989-993. Allí se añade que el Estado miembro de la OEA que haya requerido la opinión queda vinculado si decide ratificar la $\mathrm{CADH}$, pues el artículo 2o. de este instrumento le exige realizar la correspondiente adecuación de su legislación interna.

28 Así se ha reconocido explícitamente. Cfr. Nikken, Pedro, op. cit., nota 26, p. 176. 
los supuestos de los dos párrafos del artículo 64 de la $\mathrm{CADH}$, se ha dicho:

Las opiniones consultivas... tienen, en general, un valor análogo al que tienen las sentencias de los tribunales internacionales para los Estados que no han sido partes en el caso sentenciado: si bien no son directamente obligatorias para ellos, representan una interpretación auténtica del derecho internacional... que, como fuente auxiliar del mismo, debe ser tenido como norma por los Estados americanos para el cumplimiento de sus obligaciones internacionales. ${ }^{29}$

A favor de los efectos vinculantes de las opiniones consultivas se ha aducido un punto interesante: que la función consultiva de la Corte es de naturaleza jurisdiccional, ${ }^{30}$ es decir "dice lo que es derecho, o en otros términos, ejerce la juris dictio", ${ }^{31}$ y esto a pesar de que el artículo 2o. del Estatuto de la Corte habla de "función jurisdiccional" como contrapuesta a la "función consultiva", identificando jurisdiccional con contenciosa. ${ }^{32}$ Pero, por el contrario, se ha señalado que "si bien puede calificarse de $j u$ dicial en sentido amplio, no posee carácter jurisdiccional". ${ }^{33}$

Para mostrar el carácter vinculante de esas resoluciones, se ha argumentado también que el hecho de que la Corte las haya considerado y aplicado como jurisprudencia que sustenta sus sentencias en los casos contenciosos sólo se puede explicar en razón del valor y el efecto que

29 Idem.

30 Cfr. ibidem, p. 173, donde añade que "es cierto que el artículo 2 del Estatuto de la Corte parece oponer la función "jurisdiccional" a la "consultiva", pero en mi concepto tal oposición se explica porque se hizo un uso estricto del vocablo "jurisdiccional", considerándolo como sinónimo de "contencioso".

31 Idem. En el mismo sentido, cfr. Gros Espiell, Héctor, "El procedimiento contencioso ante la Corte Interamericana de Derechos Humanos, La Corte Interamericana de Derechos Humanos. Estudios y documentos, San José, Instituto Interamericano de Derechos Humanos, 1985, p. 70, y Espinal Irias, Rigoberto, "Competencia y funciones de la Corte Interamericana de Derechos Humanos", en Nieto Navía, Rafael (ed.), op. cit., nota 26, p. 125.

32 Para una crítica de tal identificación, véase, Gros Espiell, Héctor, "El procedimiento contencioso ante la Corte Interamericana", cit., nota 31, pp. 151 y 152, y Nikken, Pedro, op. cit., nota 26, p. 173.

33 Fix-Zamudio, Héctor, "Notas sobre el Sistema Interamericano de Derechos Humanos", La justicia constitucional iberoamericana, Madrid, Dykinson, 1997, p. 189. 
esas opiniones tienen en sí mismas. ${ }^{34}$ No obstante, parece que al afirmar eso se ha dado un salto gratuito en el razonamiento porque, de la incorporación en las sentencias de los criterios adoptados originalmente en las opiniones consultivas, no se sigue que éstas tengan efecto vinculante: dichas opiniones podrían haberse traído a colación dentro de una sentencia a pesar de que posean solamente el carácter de fuente material, derivado de la autoridad de la misma Corte.

Ahora bien, la Corte en una resolución reciente, mediante la cual rechaza una solicitud de opinión consultiva, coloca a las opiniones y sentencias en mismo nivel de importancia, cuando dice que no admitirá la solicitud porque "las respuestas a las preguntas planteadas por la Comisión pueden extraerse del análisis e interpretación integral del corpus jurisprudencial del Tribunal". ${ }^{35}$ Y más adelante aclara que las opiniones consultivas, y las resoluciones de los casos y las medidas provisionales integran ese corpus y "expresan la interpretación y aplicación que el Tribunal ha dado a la normativa convencional... lo cual también debe constituir una guía para la actuación de otros Estados que no son partes en el caso o las medidas". ${ }^{36}$ Como se ve, sobre todo respecto de esta última frase, la Corte ha variado su posición jurisprudencial, ${ }^{37}$ y ha llegado a un punto de encuentro con lo que muchos años antes se había señalado en la doctrina: que la experiencia de otros tribunales internacionales sugiere que éstos ejercen funciones de gran incidencia, "no importa si dictan decisiones adjudicatarias u opiniones consultivas. El efecto práctico de estas decisiones es el mismo, no obstante su diferente efecto legal". ${ }^{38}$

Sin embargo, ha de tenerse presente que, desde el punto estrictamente teórico, todavía está abierta la discusión; ${ }^{39}$ además, que ésta no radica en si esas opiniones consultivas tienen efectos jurídicos innegables: es claro

34 Cfr. Nikken, Pedro, op. cit., nota 26, p. 174.

35 Corte IDH, Resolución sobre solicitud de opinión consultiva presentada por la CIDH, 24-VI-05, considerando 12.

36 Ibidem, considerando 13.

37 Cfr. Corte IDH, "Otros tratados". Objeto de la función consultiva de la Corte, nota 5 , párrafo 51 .

38 Buergenthal, Thomas, "Las convenciones Europea y Americana: algunas similitudes y diferencias", cit., nota 5, p. 185.

39 Cfr. García Ramírez, Sergio, op. cit., nota 7, p. 1002, donde se resumen algunas de las posiciones al respecto. Sobre los efectos de las opiniones consultivas, véase también: Buergenthal, Thomas, Derechos humanos internacionales, 2a. ed., México, Ediciones Gernika, p. 224-242. 
que las tienen y también lo es que no son los mismos que los de una sentencia. El problema es dilucidar en qué sentido y para quiénes es vinculante, y si todas lo son o sólo las solicitadas sobre la base del artículo 64, párrafo 1o. de la $\mathrm{CADH}$.

\section{LA INFLUENCIA DEL TEDH EN LAS OPINIONES CONSULTIVAS: UNA APROXIMACIÓN VÁLIDA Y NECESARIA}

Para sopesar la influencia del TEDH es válido y necesario hacer una primera aproximación siguiendo un criterio preponderantemente cuantitativo.

Lo que aquí se busca es determinar si en la argumentación de las 19 opiniones consultivas que la Corte ha resuelto 40 —incluyendo la de los votos separados - ha sido invocada la jurisprudencia del TEDH, y también advertir cuáles no la mencionan, pues eso pone en evidencia los temas en los que la Corte no ha considerado pertinente seguir criterios ajenos al propio sistema regional.

$\mathrm{Al}$ ir analizando cronológicamente esas opiniones, es oportuno tener presente las diversas etapas de la historia de la Corte:

La primera abarcaría de septiembre de 1979, fecha de su instalación en San José de Costa Rica, hasta principios de 1986 en que ingresan los primeros casos contenciosos. La segunda iría de 1986 hasta 1993, en que llegan unos pocos casos y opiniones consultivas más a la Corte y se empiezan a someter las primeras solicitudes de medidas provisionales... La tercera etapa... se inicia en el año 1994, en que se intensifica el envío de casos a la Corte por la Comisión... y que termina en... junio de 2001 con la entrada en vigor del cuarto Reglamento de la Corte ${ }^{41}$ que da locus standi a las víctimas o sus representantes durante todo el proceso ante ella. A partir de junio de 2001 se inicia una cuarta etapa. ${ }^{42}$

40 Hasta agosto de 2008, véase supra nota 2.

41 Aprobado por la Corte IDH en su XLIX Periodo Ordinario de Sesiones, mediante Resolución del 24 de noviembre de 2000, el cual entró en vigor el 1o. de junio de 2001, y según la reforma parcial aprobada por la Corte en su LXI Periodo Ordinario de Sesiones, mediante Resolución del 25 de noviembre de 2003, vigente desde el 1o. enero de 2004.

42 Ventura Robles, Manuel, "La Corte Interamericana de Derechos Humanos: camino hacia un tribunal permanente", en Corte Interamericana de Derechos Humanos, El futuro de la Corte Interamericana de Derechos Humanos, 2a. ed., San José, Corte IDHACNUR, 2003, pp. 111 y 112. 


\section{Primera etapa}

Durante esta primera etapa la Corte IDH emitió siete opiniones consultivas. ${ }^{43}$ Ya desde el primer momento, el sistema europeo fue punto de referencia para la Corte IDH. Por un lado, su primer reglamento fue copia del Reglamento del TEDH de la época. ${ }^{44}$ Por otro, tanto la OC-1/82 como la OC-3/83, recogen una comparación de ambos sistemas de protección de los derechos humanos ${ }^{45}$ que destaca las diferencias de ambos órganos judiciales en lo que a las competencias consultivas se refiere. Sobre el particular, la OC-1/82, relativa a los alcances de la expresión "otros tratados" del artículo 64, párrafo 1o. de la $\mathrm{CADH}$, señala que la génesis de la redacción de ese artículo "pone de manifiesto que el Pacto de San José quiso dar a la Corte Interamericana de Derechos Humanos una competencia consultiva lo más amplia posible, sin las limitaciones del sistema europeo". ${ }^{46}$ Y la OC-3/93 afirma que la función consultiva conferida en ese artículo "es única en el derecho internacional contemporáneo... Ni la Corte Internacional de Justicia ni la Corte Europea de Derechos Humanos han sido investidas con la amplia función consultiva que la Convención ha otorgado a la Corte Interamericana". ${ }^{47}$

La Corte invoca por primera vez una sentencia del TEDH en la OC-4/84, para referirse al principio de no discriminación, señalando que

43 Para un estudio pormenorizado de las opiniones consultivas de esta primera etapa, véase Ventura, Manuel E. y Zovatto, Daniel, La función consultiva de la Corte Interamericana de Derechos Humanos. Naturaleza y principios, 1982-1987, Madrid, IIDH/Civitas, 1989, passim.

44 Y copia también del Reglamento de la Corte Internacional de Justicia. Cfr. Ventura Robles, Manuel, "La Corte Interamericana de Derechos Humanos: camino hacia un tribunal permanente", cit., nota 42, p. 121.

45 En la línea de comparar ambos sistemas, véase también Corte IDH, Ciertas atribuciones de la Comisión Interamericana de Derechos Humanos (artículos 41, 42, 44, 46, 47, 50 y 51 Convención Americana sobre Derechos Humanos). Opinión consultiva OC-13/93 del 16 de julio de 1993. Serie A núm. 13, párrafos 46 y 47; y Corte IDH, Informes de la Comisión Interamericana de Derechos Humanos, cit., nota 23, voto disidente del juez Pacheco Gómez, párrafos 17, 18 y 26. Ambas opiniones se refieren a las competencias de la CIDH.

46 Corte IDH, "Otros tratados". Objeto de la función consultiva de la Corte, cit., nota 5, párrafo 46. Cfr. ibidem, párrafos 16 y 26.

47 Corte IDH, Restricciones a la pena de muerte, cit., nota 5, párrafo 43. 
la jurisprudencia europea ha dicho que "sólo es discriminatoria una distinción cuando «carece de justificación objetiva y razonable»". ${ }_{48}$

En la OC-5/85, la Corte interpretó el alcance de la libertad de expresión establecido en el artículo 13 de la CADH y señaló la no adecuación de la Ley del Colegio de Periodistas del país solicitante - que establecía la colegiatura obligatoria - al contenido de ese artículo. En su argumentación, antes de invocar la jurisprudencia del TEDH, hizo una interpretación del artículo 13 de la CADH poniéndolo en paridad con el artículo 10 del CEDH, al menos en el sentido de que las restricciones de la libertad de pensamiento y expresión sólo pueden "vincularse con las necesidades legítimas de las sociedades e instituciones democráticas". ${ }^{49}$ Entonces, al explayarse sobre cuáles son las legítimas restricciones de la libertad de expresión, la Corte se apoyó en varias sentencias europeas que han dicho que la restricción debe ser proporcionada al interés que la motiva y ajustarse estrechamente al logro del legítimo objetivo..$^{50}$

La OC-6/86 buscaba aclarar cómo se debe entender la expresión "leyes" en el artículo 30 de la CADH, y ahí la Corte hizo una breve referencia a una sentencia europea para señalar que "el concepto de leyes no puede interpretarse en abstracto $\mathrm{y}$, en consecuencia, no debe divorciarse del contexto del orden jurídico que le presta sentido e incide en su aplicación". 51

48 Eur. Court H. R., Case "relating to certain aspects of the laws on the use of languages in education in Belgium" (merits), judgment of 23rd July 1968, pag. 34, citada en Corte IDH. Propuesta de modificación a la Constitución Política de Costa Rica relacionada con la naturalización, cit., nota 14, párrafo 56. (Las referencias de la jurisprudencia del TEDH se transcriben tal como aparecen en las respectivas opiniones consultivas).

$49 C f r$. Corte IDH, La colegiación obligatoria de periodistas, cit., nota 20, párrafo 42. Eso lo logró interpretando el artículo 13 de la CADH a la luz de diversas disposiciones del sistema interamericano, que mencionan las "instituciones democráticas", la "democracia representativa", las "sociedades democráticas" y el "desenvolvimiento democrático" como límite de los derechos. Cfr. ibidem, párrafos 42 y 43 . También utilizó como instrumento hermenéutico la DADDH. Cfr. ibidem, párrafo 44.

50 Cfr. The Sunday Times, judgment of 26 april 1979, Series A núm. 30, par. 62, p. 38; véase también Eur. Court H. R., Barthold judgment of 25 March 1985, Series A núm. 90, par. 59, p. 26, citadas en ibidem, párrafo 46 .

51 Eur. Court H.R., The Sunday Times case, judgment of 26 april 1979, Series A núm. 30, par. 47, citada en Corte IDH, La expresión "leyes" en el artículo 30 de la Convención Americana sobre Derechos Humanos. Opinión consultiva OC-6/86 del 9 de mayo de 1986. Serie A núm. 6, párrafo 20. 
En la OC-7/86, cuyo objeto de estudio es el artículo 14 de la $\mathrm{CADH}$, que se refiere al derecho de rectificación o respuesta, se plantea la cuestión sobre si es necesario desarrollar mediante una ley ese derecho o si éste existe autónomamente, derivado de modo directo de la CADH. ${ }^{52}$ Para lo que aquí interesa, es relevante el hecho de que la Corte destacó, siguiendo lo dicho en el contexto europeo, la relación que existe entre el derecho de rectificación o respuesta y la libertad de expresión. ${ }^{53}$ En su opinión separada, el juez Gros Espiell lo reiteró: "el derecho de rectificación o respuesta sólo se comprende y se explica en función de la libertad de pensamiento, expresión e información. Estos derechos forman un complejo unitario e independiente", ${ }^{54}$ y añadió que "la libertad de pensamiento y de expresión constituye uno de los elementos esenciales de una sociedad democrática y una de las condiciones primordiales de su progreso y del pleno desenvolvimiento de la personalidad de cada uno de sus miembros" y, haciendo mención de lo dicho por el TEDH, señaló que "hay que reconocerla, incluso cuando su ejercicio provoque, choque o inquiete" y que el respeto a la libertad de expresión es una exigencia del "pluralismo, la tolerancia y el espíritu abierto, sin los cuales no es posible la existencia de una sociedad democrática". ${ }^{55}$

52 El núcleo de la cuestión, brillantemente dilucidado por el juez Piza en su opinión separada, es el siguiente: ¿Debe entenderse que ese artículo consagra un derecho de rectificación o respuesta de carácter autónomo, es decir, exigible per se como derecho de la $\mathrm{CADH}$, que el Estado de Costa Rica debe respetar y garantizar en virtud del artículo 1o., inciso 1o. de esa Convención, aun en ausencia de ley interna que lo desarrolle? ¿o se trata, por el contrario, de un derecho necesitado de desarrollo por el ordenamiento interno que, por ende, no puede exigirse per se como derecho de la CADH mientras el Estado de Costa Rica, en virtud del artículo 2o. de la $\mathrm{CADH}$, tome las medidas necesarias, normativas o de otro carácter, para hacerlo plenamente eficaz? ¿o se trata, simultáneamente, de ambas cosas: un derecho exigible per se, que el Estado esté obligado, tanto a respetar y garantizar de una vez, como a desarrollar, estableciendo legalmente las condiciones a que se refiere el artículo 14, párrafo 10.? Cfr. Corte IDH, Exigibilidad del derecho de rectificación o respuesta (artículos 14.1, 1.1 y 2 Convención Americana sobre Derechos Humanos). Opinión consultiva OC-7/86 del 29 de agosto de 1986. Serie A núm. 7, Opinión separada Juez Piza, párrafo 6.

53 Cfr. Corte IDH, Exigibilidad del derecho de rectificación o respuesta, cit., nota anterior, párrafo 25 .

54 Ibidem, Opinión separada del juez Gros Espiell, párrafo 5.

55 Eur. Court H. R., Lingens case, judgment of 8 July 1986, Series A núm. 103, par. 41 , citada en idem. (El primer entrecomillado, aunque no aparece señalado en el texto de la opinión separada, también pertenece a la misma sentencia allí referida). 
En este pronunciamiento también se recogió la opinión separada del juez Piza que, al afirmar que el derecho internacional se viola tanto por acción como por omisión, invocó como apoyo de su tesis una sentencia del TEDH, que dice: "No es posible parapetarse detrás de las eventuales lagunas del derecho interno para sustraerse a los compromisos contraídos en virtud del artículo 6o. del Convenio Europeo, que consagra los derechos al debido proceso". ${ }^{56}$ De esta manera el juez deseaba señalar que la $\mathrm{CADH}$ se puede violar por ausencia de ley, y que sería el caso en que ésta fuera necesaria para lograr el efectivo ejercicio del derecho de rectificación o respuesta.

Como se ha visto, en esta primera etapa la Corte invocó la jurisprudencia del TEDH en cuatro ocasiones, pero cabe anotar que en varias hizo alguna mención del sistema europeo. ${ }^{57}$

56 Eur. Court H. R., Eckle case, of 15 july 1982 Series A núm. 51, par. 84; véase también Marckx case, judgment of 13 june 1979, Series A núm. 31, par. 3, citada en Corte IDH, Exigibilidad del derecho de rectificación o respuesta, cit., nota 52, opinión separada del juez Piza, párrafo 19.

57 Además de las comparaciones ya señaladas entre las competencias consultivas del TEDH y la Corte IDH, se hacen dos interesantes remisiones a un pronunciamiento de la Comisión Europea de Derechos Humanos. La primera para referirse a las peculiaridades de los tratados de derechos humanos: "Las obligaciones asumidas por las altas partes contratantes en la Convención [Europea] son esencialmente de carácter objetivo, diseñadas para proteger los derechos fundamentales de los seres humanos de violaciones de parte de las altas partes contratantes en vez de crear derechos subjetivos y recíprocos entre las altas partes contratantes", "Austria vs. Italy", Application núm. 788/60, European Yearbook of Human Rights, 1961, vol. 4, p. 140, citada en Corte IDH, El efecto de las reservas sobre la entrada en vigencia de la Convención Americana sobre Derechos Humanos, cit., nota 11, párrafo 29. La segunda aparece en el pasaje en el que pone de relieve la relación entre los tratados sobre derechos humanos y el orden público, y esto con el fin de señalar que la libertad de expresión en el ámbito americano es parte del "orden público primario y radical de la democracia". Corte IDH, La colegiación obligatoria de periodistas, cit., nota 20, párrafo 52. Allí la Corte cita otra parte de ese pronunciamiento que recoge las siguientes palabras del preámbulo del CEDH: "El propósito de las altas partes contratantes al aprobar la Convención no fue concederse derechos y obligaciones recíprocos con el fin de satisfacer sus intereses nacionales sino... establecer un orden público común de las democracias libres de Europa con el objetivo de salvaguardar su herencia común de tradiciones políticas, ideales, libertad y régimen de derecho", ibidem, p. 138 citada en idem. 


\section{Segunda etapa}

Durante este periodo, que va de 1986 a 1994, la Corte dividió sus esfuerzos en atender un considerable número de casos contenciosos y medidas provisionales, y dictó seis opiniones consultivas, de las cuales - salvo la OC-13/93, en la que hace una comparación entre las competencias de la CIDH y la Comisión Europea—58 no se hizo referencia al TEDH ni al sistema europeo en general.

Todas las opiniones se refieren a aspectos muy puntuales del sistema interamericano. Unas son sobre las exigencias de la propia $\mathrm{CADH}$ en materia de las garantías judiciales en estados de emergencia, ${ }^{59}$ del debido proceso - la doble instancia en materia penal $-{ }^{60} \mathrm{y}$ del agotamiento de recursos internos. ${ }^{61}$ Otras son relativas a las competencias de sus órganos: los alcances de diversas atribuciones de la $\mathrm{CIDH}^{62}$ y la posibilidad de que la Corte interprete, en el ejercicio de su función consultiva, la DADDH. ${ }^{63}$

\section{Tercera etapa}

Como se ha dicho, esta etapa se inicia en 1994 y termina en junio de 2001, con la entrada en vigor del cuarto Reglamento de la Corte. Durante estos años este órgano dictó la OC-14/94, sobre la responsabilidad inter-

58 Corte IDH, Ciertas atribuciones de la Comisión Interamericana de Derechos $\mathrm{Hu}-$ manos, cit., nota 45, párrafos 46 y 47.

59 Corte IDH, El hábeas corpus bajo suspensión de garantías (artículos 27.2; $25.1 \mathrm{y}$ 7.6 Convención Americana sobre Derechos Humanos). Opinión consultiva OC-8/87 del 30 de enero de 1987. Serie A núm. 8, y Corte IDH, Garantías judiciales en estados de emergencia (artículos 27.2; 25 y 80. Convención Americana sobre Derechos Humanos). Opinión consultiva OC-9/87 del 6 de octubre de 1987. Serie A núm. 9.

60 Corte IDH, Compatibilidad de un proyecto de ley con el artículo 8.2.h de la Convención Americana sobre Derechos Humanos, nota 15, aunque ésta es más bien una resolución de no dar respuesta a la consulta.

61 Corte IDH, Excepciones al agotamiento de los recursos internos (artículos 46.1; 46.2.a y 46.2.b Convención Americana sobre Derechos Humanos). Opinión consultiva OC-11/90 del 10 de agosto de 1990. Serie A núm. 11.

62 Corte IDH, Ciertas atribuciones de la Comisión Interamericana de Derechos Humanos, cit., nota 45.

63 Corte IDH, Interpretación de la Declaración Americana de los Derechos y Deberes del Hombre en el marco del artículo 64 de la Convención Americana sobre Derechos Humanos, cit., nota 12. 
nacional por expedición y aplicación de leyes violatorias del Pacto de San José. Se trata de un tema muy propio del sistema interamericano, pues en el CEDH no existe una norma análoga al artículo 2o. de la CADH. ${ }^{64}$ Sin embargo, cuando en la opinión se afirmó que "la Comisión no puede someter a la Corte casos de leyes que no sean de aplicación inmediata y que aún no hayan sido aplicadas", ${ }^{65}$ se hizo referencia a tres sentencias del TEDH que señalan que la denuncia que se presenta ante la Comisión debe ser sobre una violación concreta de derechos humanos respecto de individuos determinados, ${ }^{66}$ que denuncien violaciones concretas y que hayan agotado los recursos internos. ${ }^{67}$ En definitiva, se trató así de perfilar el concepto de víctima.

La OC-15/97, que se refiere a los informes de la CIDH, es la única opinión de esta época en la que se omitió toda invocación a la jurisprudencia europea. ${ }^{68}$

La OC-16/99 buscó determinar si el artículo 36, inciso 1o., subincisos b y c de la Convención de Viena sobre Relaciones Consulares - que establece el deber de informar al extranjero privado de libertad su derecho a contar con la asistencia consular - ha de considerarse parte de las exigencias del debido proceso, establecidas en el artículo 14 del Pacto Internacional de Derechos Civiles y Políticos, el artículo 3o. de la Carta de la OEA y el artículo II de la DADDH.

Como bien se ha señalado, ${ }^{69}$ esta solicitud fue admisible gracias a la interpretación extensiva que la Corte hiciera en la OC-1/82 respecto de su propia competencia consultiva, en el sentido de que ésta incluye también tratados cuyo objeto principal no son los derechos humanos o cuyo origen sea ajeno al sistema interamericano.

64 Sobre el particular, aunque no referido a esta resolución, $c f r$. Corte IDH, Exigibilidad del derecho de rectificación o respuesta, cit., nota 52, opinión separada del juez Gros Espiell, párrafo 6.

$65 C f r$. Corte IDH, Responsabilidad internacional por expedición y aplicación de leyes violatorias de la Convención (artículos 1o. y 20. Convención Americana sobre Derechos Humanos). Opinión consultiva OC-14/94 del 9 de diciembre de 1994. Serie A núm. 14, párrafo 45 .

66 Cfr. ibidem, párrafo 47.

67 Cfr. ibidem, párrafo 45.

68 Hay sólo una comparación de la CIDH con la Comisión Europea de Derechos Humanos. Cfr. Corte IDH, Informes de la Comisión Interamericana de Derechos Humanos, cit., nota 23, voto disidente de juez Pacheco Gómez, párrafos 16, 18 y 26.

69 Cfr. Nikken, Pedro, op. cit., nota 26, pp. 166 y 167. 
En la OC-16/99 se citaron tres sentencias del $\mathrm{TEDH}^{70} \mathrm{y}$ dos adicionales en el voto concurrente del juez Cançado Trindade ${ }^{71}$ para referirse al criterio hermenéutico de interpretación evolutiva, un tema importante desde el punto de vista teórico y práctico, que merecería un análisis por separado. Baste aquí decir que en la OC-10/89, siguiendo a la Corte Internacional de Justicia, ${ }^{72}$ la Corte IDH ya había aplicado este criterio, pero con relación a la naturaleza del instrumento. Entonces afirmó que en el ejercicio de su función consultiva era competente para interpretar la DADDH, aunque ésta no fuera en puridad de principios un tratado, porque los instrumentos se deben interpretar según el contexto del momento en que se interpretan y no según el contexto en el que fueron creados. ${ }^{73}$

En la OC-16/99, al invocar de nuevo a la Corte Internacional de Justicia, ${ }^{74}$ la Corte aplica ese criterio hermenéutico, ya no a la naturaleza sino al contenido del instrumento. Además unió al criterio de interpretación evolutiva la noción de corpus iuris gentium. Fue entonces cuando trajo a colación la jurisprudencia europea para afirmar que las normas que integran el corpus del derecho internacional de los derechos humanos deben interpretarse según la evolución de los tiempos y las condiciones de vida actuales. ${ }^{75}$ De ese modo, resolvió que el artículo 36, inciso 1o., subinciso

70 Eur. Court H. R., Tyrer v. United Kingdom, judgment of 25 April 1978, Series A núm. 26, pp. 15-16, par. 31, Eur. Court H. R., Marckx case, judgment of 13 June 1979, Series A núm. 31, p. 19, párrafo 41; Eur. Court H. R., Loizidou v. Turkey (Preliminary Objections) judgment of 23 March 1995, Series A núm. 310, p. 26, par. 71, citadas en Corte IDH, El derecho a la información sobre la asistencia consular en el marco de las garantías del debido proceso legal, cit., nota 3, párrafo 114.

71 Eur. Court H. R., Airey versus Irlanda (1979) y Eur. Court H. R., Dudgeon versus Reino Unido (1981). Cfr. Corte IDH, El derecho a la información sobre la asistencia consular en el marco de las garantías del debido proceso legal, cit., nota 3, voto concurrente del juez Cançado Trindade, párrafo 7.

72 "Un instrumento internacional debe ser interpretado y aplicado en el cuadro del conjunto del sistema jurídico en vigor en el momento en que la interpretación tiene lugar". Legal Consequences for States of the Continued Presence of South Africa in Namibia (South West Africa) notwithstanding Security Council Resolution 276 (1970), Advisory Opinion, I.C.J. Reports 1971, pags. 16-31, citada en Corte IDH, Interpretación de la Declaración Americana de los Derechos y Deberes del Hombre en el marco del artículo 64 de la Convención Americana sobre Derechos Humanos, nota 12, párrafo 37.

73 Idem.

74 Cfr. Corte IDH, El derecho a la información sobre la asistencia consular en el marco de las garantías del debido proceso legal, cit., nota 3, párrafo 113.

75 Ibidem, párrafo 114. 
b mencionado "permite que adquiera eficacia, en los casos concretos, el derecho al debido proceso legal consagrado en el artículo 14 del Pacto Internacional de Derechos Civiles y Políticos". ${ }^{76}$

En este pronunciamiento también se remitió a una sentencia del TEDH para indicar que, tanto a nivel normativo como jurisprudencial, se muestra "una clara tendencia restrictiva a la aplicación de la pena de muerte hacia su supresión final". ${ }^{77}$

Termina así una etapa más de la historia de la Corte, pero conviene recordar que durante este periodo entra en vigor el Protocolo 11 del $\mathrm{CEDH},{ }^{78}$ que modifica el diseño institucional y procesal de todo el sistema europeo, lo que incidirá directamente en el aumento de jurisprudencia proveniente del TEDH.

\section{Cuarta etapa}

Esta época comenzó con la entrada en vigor de ese nuevo reglamento de la Corte IDH, ${ }^{79}$ que vino de modo concomitante al reglamento de la CIDH. ${ }^{80}$ Las reformas más significativas se dieron en el campo de la

76 Ibidem, parte resolutiva, párrafo 6 .

77 Eur. Court H. R., Soering case, decisión del 26 de enero de 1989, Series A núm. 161, par. 102, citada en ibidem, párrafo 134.

78 Protocolo 11 de reforma al CEDH, firmado el 11 de mayo de 1994, entró en vigor el 10. de noviembre de 1998. Sobre los aspectos institucionales y de procedimiento del sistema europeo tanto anteriores como posteriores a este protocolo, véase entre otros, Arriaga, Inés y Zoco, Cristina, "La reforma del sistema de protección de los derechos del hombre instaurado por el convenio europeo de 1950: el protocolo núm. 11", Humana Iura, Suplemento de Derechos Humanos de la Revista Persona y Derecho, núm. 5, 1995, Pamplona, passim.

79 Véase nota 41. Sobre ese nuevo reglamento, véase, Cançado Trindade, Antonio Augusto, "El nuevo Reglamento de la Corte Interamericana de Derechos Humanos (2000): la emancipación del ser humano como sujeto del derecho internacional de los derechos humanos", Revista IIDH, San José, vol. 30-31, 2001, passim, pp. 45-71. También, Gialdino, Rolando E., "La Corte Interamericana de Derechos Humanos y sus reglamentos", Anuario Latinoamericano de Derecho Constitucional, vol. 2, 2006, Montevideo, passim.

80 Aprobado por la Comisión en su 109o. Periodo Extraordinario de Sesiones, celebrado del 4 al 8 de diciembre de 2000, y modificado en su 116o. Periodo Ordinario de Sesiones, celebrado del 7 al 25 de octubre de 2002, en su 1180. Periodo Ordinario de Sesiones, celebrado del 6 al 24 de octubre de 2003 y en su 126o. Periodo Ordinario de Sesiones celebrado del 16 al 27 de octubre de 2006. 
competencia contenciosa de la Corte, y éste ha sido uno de los factores por los que ha aumentado desde entonces exponencialmente el número de casos de esta naturaleza tramitados por ese órgano judicial. ${ }^{81}$ En lo que se refiere a la competencia consultiva, se dictaron pocas pero importantes opiniones.

La OC-17/02 es la que hasta el momento ha hecho más referencia a la jurisprudencia del TEDH. En esa opinión la Corte citó 25 sentencias de ese tribunal. ${ }^{82}$ Fue solicitada por la CIDH, quien originalmente pidió la interpretación de los artículos 8o. y 25 de la CADH - que tratan sobre las garantías del debido proceso y la protección judicial, respectivamente- en relación con el artículo 19 de la CADH. Éste señala: "Todo niño tiene derecho a las medidas de protección que su condición de menor requieren por parte de su familia, de la sociedad y del Estado". Lo que estaba por dilucidar era si esas medidas de protección, de las que habla ese artículo 19, constituyen algún límite al arbitrio o a la discrecionalidad de los Estados, al aplicar a los niños el contenido de los artículos 80. y 25 de la CADH. Además, se solicitó la formulación de criterios generales válidos sobre la materia dentro del marco de la CADH. ${ }^{83}$ En un segundo momento, la $\mathrm{CIDH}$ "amplió su planteamiento y requirió la interpretación de otros tratados, principalmente la Convención sobre los Derechos del Niño, en cuanto estos últimos podían contribuir a fijar el alcance de la Convención Americana". 84

Esta OC-17/02, al entrar en temas de fondo, comenzó definiendo el concepto de niño; después se refirió a la igualdad y ahí hizo la primera invocación a la jurisprudencia europea, que es en realidad una reiteración

81 Cfr. Ventura Robles, Manuel, "La Corte Interamericana de Derechos Humanos: necesidad inmediata de convertirse en un tribunal permanente, Corte Interamericana de Derechos Humanos", La Corte Interamericana de Derechos Humanos. Un cuarto de siglo: 1979-2004, San José, Corte Interamericana de Derechos Humanos, 2005, passim y la jurisprudencia de la Corte IDH en el ejercicio de su competencia contenciosa que aparece en el sitio www.corteidh.or.cr.

82 Corte IDH, Condición jurídica y derechos humanos del niño, cit., nota 20. Algunas, en más de una ocasión, pues se pronuncian sobre diversos temas. Por ser estas invocaciones tan numerosas, sólo se indicarán los párrafos de esta opinión que refieren esas sentencias.

83 Cfr. Corte IDH, Condición jurídica y derechos humanos del niño, cit., nota 20, párrafos 1 y 18.

84 Ibidem, párrafo 20. 
de la que ya había hecho en la OC-4/84. ${ }^{85}$ Esta vez amplió el número de sentencias en las que se ha establecido que "no toda distinción de trato puede considerarse ofensiva, por sí misma, de la dignidad humana", pues sólo es discriminatoria una distinción cuando "carece de justificación objetiva y razonable". 86

Luego el pronunciamiento tituló el siguiente apartado así: "Deberes de la familia, la sociedad y el Estado. Familia como núcleo central de protección". Aquí afirmó que

en principio, la familia debe proporcionar la mejor protección de los niños contra el abuso, el descuido y la explotación. Y el Estado se halla obligado no sólo a disponer y ejecutar directamente medidas de protección de los niños, sino también a favorecer, de la manera más amplia, el desarrollo y la fortaleza del núcleo familiar. ${ }^{87}$

La Corte señaló que el reconocimiento de la familia como elemento natural y fundamental de la sociedad, con derecho a la protección de la sociedad y el Estado, es un principio fundamental del derecho internacional de los derechos humanos, reconocido en diferentes instrumentos internacionales. ${ }^{88}$ Después añadió una frase llena de sentido: "Es importante considerar el alcance que tiene el concepto de familia para radicar los deberes y facultades a los que hacemos referencia". ${ }^{89} \mathrm{Y}$ entonces indicó que el TEDH "ha sostenido en diversas ocasiones que el concepto de vida familiar «no está reducid[o] únicamente al matrimonio y debe abarcar otros lazos familiares de hecho donde las partes tienen vida en común por fuera del matrimonio»»". ${ }^{90}$

85 Corte IDH, Propuesta de modificación a la Constitución Política de Costa Rica relacionada con la naturalización, nota 14 , párrafo 55 .

86 Corte IDH, Condición jurídica y derechos humanos del niño, cit., nota 20, párrafo 46 .

87 Ibidem, párrafo 66.

88 Ibidem, párrafos 67 y 68 .

89 Ibidem, párrafo 69.

90 Eur. Court H. R., Keegan v. Ireland, judgment of 26 may 1994, Series A núm. 290, par. 44; y Eur. Court H. R., Case of Kroon and Others v. The Netherlands, judgment 27th October, 1994, Series A núm. 297-C, par. 30, invocadas en idem. Sobre esto cabe hacer notar que la jurisprudencia europea está definiendo el concepto de vida familiar, sin embargo, la Corte IDH invoca ese pronunciamiento para definir el concepto de familia. 
Posteriormente, esta opinión consultiva se refirió a la separación del niño de su familia, afirmando que cabe sólo de modo excepcional. Aquí de nuevo se mencionó la jurisprudencia de Estrasburgo. Ésta ha analizado el asunto desde el prisma del artículo 8o. del CEDH, que reconoce el derecho al respeto a la vida privada y familiar. El TEDH ha dicho que "el disfrute mutuo de la convivencia entre padres e hijos constituye un elemento fundamental en la vida de familia"; 91 y "que aun cuando los padres estén separados de sus hijos la convivencia familiar debe estar garantizada". ${ }^{92}$ Además, ha señalado que "las medidas que impidan ese goce constituyen una interferencia en el derecho protegido en el artículo 8o. de la Convención", ${ }^{93}$ que el contenido esencial de este precepto es la protección del individuo frente a la acción arbitraria de las autoridades públicas y, también, que una de las interferencias más graves es la que tiene por resultado la división de una familia. ${ }^{94}$ Finalmente, el TEDH ha subrayado que, cualquier decisión relativa a la separación del niño de su familia, debe estar justificada por el interés del niño. ${ }^{95}$

Apoyándose en la jurisprudencia europea, la Corte dijo que "las autoridades poseen, en algunos casos, facultades muy amplias para resolver lo que mejor convenga al cuidado del niño". ${ }^{96}$ Pero acertadamente agregó, también con base en esa jurisprudencia, que "debe existir un balance justo entre los intereses del individuo y los de la comunidad, así como entre los del menor y sus padres", ${ }^{97} \mathrm{y}$ "que la autoridad que se reconoce a la familia no implica que ésta pueda ejercer un control arbitrario sobre el niño, que pudiera acarrear daño para la salud y el desarrollo del menor". 98

El pronunciamiento se refirió después a las obligaciones positivas estatales en esta materia e invocó la jurisprudencia del TEDH para señalar diversos deberes del Estado: resguardar el rol preponderante de la familia en la protección del niño; prestar asistencia a la familia, mediante

91 Cfr. Corte IDH, Condición jurídica y derechos humanos del niño, cit., nota 20, párrafo 72 , cinco sentencias invocadas.

92 Idem, tres sentencias invocadas.

93 Idem, cuatro sentencias invocadas.

94 Idem, pero no se mencionan las sentencias que recogen esa línea jurisprudencial.

95 Ibidem, párrafo 73 , tres sentencias invocadas.

96 Ibidem, párrafo 74, siete sentencias invocadas.

97 Idem, cuatro sentencias invocadas.

98 Idem, cuatro sentencias invocadas. 
la adopción de medidas que promuevan la unidad familiar; ${ }^{99}$ reconocer el derecho del niño a ser protegido contra interferencias de actores no estatales como el maltrato de uno de los padres ${ }^{100} \mathrm{y}$, además, el deber de intervenir para proteger a "los niños han sido descuidados por sus padres y carecen de satisfacción [sic] para afrontar sus necesidades sociales básicas". 101

En el último apartado la Corte desarrolló un amplio espectro de derechos del debido proceso y protección judicial de los niños, que fue originalmente el objeto de la consulta. La jurisprudencia de Estrasburgo se trajo a colación para hablar del principio contradictorio - que debe cumplirse tanto si el niño interviene por sí, como cuando lo hace mediante representantes-, ${ }^{102}$ y a los límites del principio de publicidad. Sobre éste indicó que "a los niños acusados de crímenes debe respetárseles totalmente su privacidad en todas las etapas del proceso". ${ }^{103}$

La OC-18/03 se refiere a la condición jurídica y derechos de los migrantes indocumentados. En esta ocasión, la Corte invocó siete sentencias del TEDH. La opinión dedicó un apartado a desarrollar el alcance de la obligación de los Estados de respetar y garantizar los derechos humanos. Allí señaló que la jurisprudencia europea ha indicado que el CEDH no sólo obliga a las altas autoridades de los Estados parte a respetar los derechos y libertades que contiene sino que, con el fin de garantizar el disfrute éstos, aquellas autoridades deben además prevenir o reparar cualquier violación a niveles subordinados. ${ }^{104}$

En esta opinión, al ocuparse del principio de igualdad y no discriminación, la Corte dijo de nuevo, con palabras de la sentencia que había citado en la OC-4/04, que "no toda distinción de trato puede considerarse ofensiva, por sí misma, de la dignidad humana", y que sobre la base de "los principios que pueden deducirse de la práctica jurídica de un gran número de Estados democráticos", el TEDH ha advertido que sólo es

99 Ibidem, párrafo 88 , tres sentencias invocadas.

100 Ibidem, párrafo 90, una sentencia invocada.

101 Idem, una sentencia invocada.

102 Ibidem, párrafo 132, tres sentencias invocadas.

103 Eur. Court H. R., Case T. v. The United Kingdom, judgment of 16 december, 1999 (s. n.), par. 74, citada en ibidem, párrafo 134.

104 Eur. Court H. R., Case of Ireland v. the United Kingdom, judgment of 18 january 1978. Series A, núm. 25, par. 239, referida en Corte IDH, Condición jurídica y derechos de los migrantes indocumentados, cit., nota 20, párrafo 80. 
discriminatoria una distinción cuando "carece de justificación objetiva y razonable". ${ }^{105}$ Además añadió tres sentencias europeas que refuerzan esa línea jurisprudencial y que son las mismas que invocó en la OC 17/02.106 Lo que varió esta vez respecto de las otras ocasiones en las que la Corte se ha referido a este principio, es que en ésta se recogen unos párrafos muy significativos de la sentencia citada en la OC-4/84. Uno de éstos dice:

Una diferencia de trato en el ejercicio de un derecho establecido en la Convención no sólo debe buscar un fin legítimo: el artículo 14 se viola igualmente cuando se establece de manera clara que no hay una relación razonable de proporcionalidad entre los medios utilizados y el fin que se busca llevar a cabo. ${ }^{107}$

Un criterio de no menor entidad es el que contiene otro párrafo de esa misma sentencia, que advierte las consecuencias de la naturaleza subsidiaria de los sistemas internacionales de protección de los derechos:

En su intento de encontrar en un caso concreto si ha habido o no una distinción arbitraria, la Corte [europea] no puede hacer caso omiso de los aspectos jurídicos y fácticos que caracterizan la vida de la sociedad en el Estado que, como parte contratante, tiene que responder por la medida en discusión. Al hacerlo, no puede asumir el papel de las autoridades nacionales competentes, ya que perdería de vista la naturaleza subsidiaria de la maquinaria internacional de aplicación colectiva establecida por la Convención. Las autoridades nacionales son libres de elegir las medidas que consideren apropiadas en las

105 Eur. Court H. R., Case "relating to certain aspects of the laws on the use of languages in education in Belgium" v. Belgium, judgment of 23rd july 1968. Series A 1968, par. 10, citada en ibidem, párrafo 89.

106 Eur. Court H. R., Case of Willis v. The United Kingdom, jugdment of 11 june, 2002, par. 39; Eur. Court H. R., Case of Wessels-Bergervoet v. The Netherlands, jugdment of 4th june, 2002, par. 46; Eur. Court H. R., Case of Petrovic v. Austria, judgment of 27th of march, 1998, Reports 1998-II, par. 30; citadas en idem, y en Corte IDH, Condición jurídica y derechos humanos del niño, cit., nota 20, párrafo 46.

107 Eur. Court H. R., Case "relating to certain aspects of the laws on the use of languages in education in Belgium" v. Belgium, judgment of 23rd july 1968. Series A, 1968, par. 10, citada en Corte IDH, Condición jurídica y derechos de los migrantes indocumentados, cit., nota 20, párrafo 90 . 
materias sometidas a la Convención. El análisis de la Corte se limita a la conformidad de dichas medidas con los requisitos de la Convención. ${ }^{108}$

Como es natural, uno de los apartados de la opinión se refiere específicamente a los derechos de los trabajadores migrantes indocumentados. En este contexto, la Corte hacer ver que la $\mathrm{CADH}$ - de modo análogo a lo que la jurisprudencia europea ha dicho respecto del CEDH - tiene eficacia en las relaciones entre particulares. ${ }^{109} \mathrm{Y}$, a modo de ejemplo, trae dos sentencias europeas: una relativa a la libertad de asociación, que incluye la libertad negativa de pertenencia a un sindicato, ${ }^{110} \mathrm{y}$ otra al derecho al respeto a la vida privada y familiar, que supone la necesidad de que el Estado exija eficazmente a los individuos a abstenerse de toda interferencia que lesione tal derecho. ${ }^{111}$

Por otro lado, el voto concurrente del juez Cançado Trindade menciona dos sentencias del TEDH: una, para referirse al principio de igualdad y no discriminación, en apoyo de la tesis de que ha emergido el derecho autónomo a la igualdad; y otra, para señalar que las prohibiciones de las normas de ius cogens alcanzan las violaciones potenciales a los derechos. ${ }^{112}$

En la última opinión consultiva emitida por la Corte no hay referencia alguna al TEDH. ${ }^{113}$

108 Idem.

109 Ibidem, párrafo 143.

110 Eur. Court H. R., Case of Young, James and Webster v. The United Kingdom, (Merits) judgment of 13 August 1981. Series A núm. 44, pars. 48 to 65, citada en Corte IDH, Condición jurídica y derechos de los migrantes indocumentados, cit., nota 20, párrafo 143 .

111 Eur. Court H. R., Case of $X$ and $Y$ v. The Netherlands (Merits), judgment of 26 march 1985. Series A núm. 91, par. 23, citada en idem.

112 Ibidem, voto concurrente del juez Cançado Trindade, párrafos 61 y 69, respectivamente.

113 Cfr. Corte IDH, Control de legalidad en el ejercicio de las atribuciones de la Comisión Interamericana de Derechos Humanos (artículos 41 y 44 a 51 de la Convención Americana sobre Derechos Humanos). Opinión consultiva OC-19/05 del 28 de noviembre de 2005. Serie A núm. 19. 


\section{AlgunOS FACTORES QUE HAN INCIDIDO EN LA RECEPCIÓN DE LA JURISPRUDENCIA EUROPEA}

Corresponde ahora preguntarse cuáles factores han contribuido a que buena parte de las opiniones consultivas hayan invocado la jurisprudencia del TEDH. Con carácter hipotético se podrían señalar los siguientes: la etapa en que fueron dictadas las opiniones, la integración del órgano - asunto naturalmente unido al anterior-, la influencia de los amici curiae y el tema sobre el que versa la opinión.

\section{La etapa en que fueron dictadas}

Como se ha visto, las opiniones que invocan alguna sentencia del TEDH son las siguientes: de la primera etapa, las que se refieren a una propuesta de modificación a la Constitución Política de Costa Rica relacionada con la naturalización (OC-4/84); a la colegiación obligatoria de periodistas (OC-5/85); a la expresión "leyes" en el artículo 30 de la CADH (OC-6/86), y a la exigibilidad del derecho de rectificación o respuesta (OC-7/86). De la segunda etapa, ninguna y de la tercera, aquellas cuyo objeto son, respectivamente, la responsabilidad internacional por expedición y aplicación de leyes violatorias de la CADH (OC-14/94), y el derecho a la información sobre la asistencia consular en el marco de las garantías del debido proceso legal (OC-16/99). De la última etapa, las relativas a la condición jurídica y derechos del niño (OC-17/02) y a la condición jurídica y derechos de los migrantes indocumentados (OC18/03).

Como se puede observar, si bien en las últimas etapas hay una mayor recurrencia a la jurisprudencia del TEDH, el crecimiento no es tan considerable. Es más, se puede advertir que el número de opiniones de la primera época son siete y en cuatro de éstas hay invocación; la proporción es similar si se suman el número de opiniones de las últimas etapas juntas: de seis opiniones, hay invocaciones en cuatro de éstas. Además no se ha de perder de vista el amplio arco correspondiente a la segunda etapa en la que no hubo referencia alguna. Ahora bien, lo que sí varía significativamente es el número de sentencias europeas mencionadas en cada una de esas opiniones: las primeras invocaban una o dos sentencias, en cambio, en las últimas se aumenta el número: tres en la OC-16/99, 25 en la OC-17/02 y siete en la OC-18/03. Sin embargo, pudo haber influido la 
entrada en vigor del Protocolo 11. En efecto, de las 25 sentencias citadas en la OC-17/02, 13 son posteriores a ese hecho; pero por otro lado, si éste hubiese sido tan determinante, se habría dado un incremento ininterrumpido de sentencias invocadas a partir de la OC-16/99.

\section{La integración del órgano}

En las primeras cinco opiniones intervinieron prácticamente los mismos jueces: Reina, Nikken, Monroe, Cisneros, Piza, Buergenthal y Nieto. Entre esas opiniones, dos contienen invocaciones y tres hacen mención del sistema europeo.

En la OC-16/99 forman parte del órgano los jueces Salgado, Pacheco, Cançado Trindade, Jackman, Abreu y García. Esa integración se mantiene casi intacta hasta la OC-18/03, y en las tres opiniones consultivas se hace referencia a la jurisprudencia de Estrasburgo.

De manera que podría concluirse que la recurrencia a la jurisprudencia del TEDH está determinada por quiénes son los miembros del órgano, y no parece extraño que sea así, pues en la redacción de los textos jurisprudenciales influye la formación de los jueces: en este caso, su conocimiento de otros sistemas - el universal y el europeo-; su dominio de otras lenguas, su formación humanística, su apertura cultural, etcétera. No obstante, tal apreciación debe matizarse, porque, por ejemplo, las OC-8/87 y OC-9/87, que no contienen ningún señalamiento a dicha jurisprudencia, fueron suscritas por los mismos jueces que lo hicieron en la OC-7/86. Aun así, no es aventurado afirmar que la integración de la Corte incide en la receptividad de la jurisprudencia europea.

\section{La intervención de los amici curiae}

La figura del amicus curiae ${ }^{114}$ se abre paso y democratiza las instancias judiciales. ${ }^{115}$ Este hecho de notable interés para la sociología jurídica, no deja de tenerlo también para el derecho procesal, porque se trata

114 Sobre la figura en la Corte IDH, véase, Moyer, Charles, "The Role of Amicus Curiae in the Inter-American Court of Human Rights", La Corte Interamericana de Derechos Humanos. Estudios y Documentos, cit., nota 31, pp. 103-114.

115 Sobre éstas y otras ventajas, y los riesgos de la utilización de esta figura, $c f r$. Bazán, Víctor, “Amicus curiae, transparencia del debate judicial y debido proceso", Anuario de Derecho Constitucional Latinoamericano, Montevideo, vol. 1, 2004, pp. 278-280. 
de la utilización de una figura más propia del contexto contencioso. Sin embargo, el artículo 63, párrafo 3o. del Reglamento de la Corte, claramente prevé la posibilidad de la intervención del amicus curiae en el ejercicio de su función consultiva y este cauce ha sido aprovechado desde la primera opinión consultiva. De hecho, de las 19 opiniones consultivas, sólo en las OC-4/84 y OC-12/91116 no hubo participación de amici curiae y, en varias, el número de éstos ya había sido bastante significativo. ${ }^{117}$ Pero sobre la influencia de los amici curiae, lamentablemente no es posible hacer un juicio certero respecto de la totalidad de las opiniones consultivas, pues sólo a partir de la OC-17/02, relativa a la condición jurídica y derechos del niño, ${ }^{118}$ se incorpora al texto de la opinión un resumen de los escritos e intervenciones orales realizadas por los amici curiae. Entonces las observaciones que aquí se pueden hacer sobre la posible repercusión de los argumentos de éstos en los de los jueces - desde el prisma que aquí se ha utilizado: la influencia del TEDH en el ejercicio de la función consultiva de la Corte IDH - se circunscriben a los tres últimos pronunciamientos.

En las intervenciones realizadas por los amici curiae en las opiniones consultivas OC-17/02 y OC-19/05, no hay ninguna referencia a la jurisprudencia europea. En relación con esta última, tal omisión no causa extrañeza pues, como se ha anotado líneas atrás, tampoco el razonamiento del órgano refiere sentencias europeas; pero respecto de la primera sí, porque es la opinión consultiva que ha invocado más sentencias del TEDH.

En cambio, en las intervenciones realizadas en el procedimiento de la OC-18/03, hay varias alusiones a esa jurisprudencia. Lo interesante es que éstas son las mismas que aparecen en dos votos particulares. En efecto, el argumento utilizado por Clínicas Jurídicas del Colegio de Jurisprudencia de la Universidad San Francisco de Quito es recogido en el

116 Y ésta es en realidad una resolución en la que la Corte decide no darle respuesta a la consulta, del mismo modo que sucedió con las resoluciones de solicitud de opinión del 10 de octubre de 2005 y del 24 de noviembre de 2005, respectivamente. Estas últimas no fueron catalogadas por la Corte como opiniones consultivas, por tanto, no les otorgó un número consecutivo en la Serie A, sino simplemente como resoluciones. Cfr. www.corteidh.or.cr.

117 Corte IDH, La colegiación obligatoria de periodistas, cit., nota 20; Corte IDH, Ciertas atribuciones de la Comisión Interamericana de Derechos Humanos, cit., nota 45.

118 Corte IDH, Condición jurídica y derechos humanos del niño, cit., nota 20, párrafo 15. 
voto concurrente del juez Abreu Burelli. ${ }^{119}$ Es lamentable que en ninguno de los dos casos se cita una sentencia concreta que avale lo que señala que el TEDH ha dicho; además, parece que el amicus curiae advierte sobre cuáles serían las consecuencias - los efectos - en el caso de que se acepte que el principio de igualdad y no discriminación es una norma de ius cogens y, al hacerlo, se remite a la jurisprudencia europea sobre los efectos de esas normas; en cambio, el voto salvado afirma que el principio de igualdad y no discriminación es una norma de ius cogens, y entonces refiere lo que el amicus curiae indica que el TEDH ha sostenido sobre los efectos de este tipo de normas.

En esa misma opinión consultiva, hay otras dos referencias a la jurisprudencia europea hecha por un amicus curiae y ambas se dan en relación con el principio de igualdad y no discriminación. El Centro por la Justicia y el Derecho Internacional (CEJIL), argumenta que "la Corte Europea ha analizado tratamientos discriminatorios en razón de la orientación sexual y la edad". ${ }^{120}$ Y luego añade que "en el caso Gaygusuz v. Austria la Corte Europea indicó que deben alegarse razones de mucho peso para que la diferencia de trato, fundada sólo en la nacionalidad, sea considerada compatible con la Convención Europea". ${ }^{121}$ Esta misma sentencia se encuentra en el voto del juez Cançado Trindade para aducir que "se ha de considerar discriminatoria cualquier distinción que no tenga un propósito legítimo, o una justificativa objetiva y razonable, y que no guarde una relación de proporcionalidad entre su propósito y los medios empleados"122 y que, además, se está dando en el derecho internacional de los derechos humanos contemporáneo "la emergencia y evolución de un verdadero derecho a la igualdad". ${ }^{123}$

119 Corte IDH, Condición jurídica y derechos de los migrantes indocumentados, cit., nota 20, párrafo 47, Clínicas Jurídicas del Colegio de Jurisprudencia de la Universidad San Francisco de Quito, y voto concurrente del juez Abreu Burelli, parte I.

120 Corte IDH, Condición jurídica y derechos de los migrantes indocumentados, cit., nota anterior; Centro por la Justicia y el Derecho Internacional (CEJIL). Sin embargo, aquí tampoco se menciona sentencia alguna.

121 Idem.

122 Corte IDH, Condición jurídica y derechos de los migrantes indocumentados, nota 20, y voto concurrente del juez Cançado Trindade, párrafo 60.

123 Ibidem, párrafo 61. La cursiva es del original. 


\section{El tema de la consulta}

Como se ha visto, la Corte ha utilizado sentencias del TEDH en apoyo de sus argumentos sobre la libertad de expresión (OC-5/85) y la relación de ésta con el derecho de rectificación o respuesta (OC-7/86); el principio de no discriminación (OC-4/84, OC-17/02, OC-18/03); la necesidad de interpretar el concepto de leyes según su contexto jurídico (OC-6/86) y el concepto de víctima (OC-14/94); los criterios hermenéuticos (OC-16/ 99); diversos derechos del niño y asuntos conexos (OC-17/02); la naturaleza subsidiaria de los sistemas internacionales de protección de los derechos $\mathrm{y}$, finalmente, sobre la eficacia de la $\mathrm{CADH}$ en las relaciones entre particulares (ambas en la OC-18/03).

Por otro lado, dos opiniones separadas (ambas de la OC-7/86) mencionan la jurisprudencia del TEDH: el juez Gros Espiell para señalar la relación entre el derecho de rectificación o respuesta y el de libertad de expresión, y entre éste y la democracia; y el juez Piza para señalar que el Estado puede violar el derecho internacional por acción o por omisión. El juez Cançado Trindade lo hace en dos votos concurrentes: en uno, para referirse al criterio hermenéutico de interpretación evolutiva (OC16/99) y, en otro, para hacerlo tanto sobre la igualdad y no discriminación como sobre la tesis de que las prohibiciones de las normas de ius cogens alcanzan las violaciones potenciales a los derechos (OC-18/03).

Se puede observar que en la mayoría de los casos se trata de temas de derecho sustantivo o de principios basilares, que son susceptibles de ser comunes a cualquier sistema de protección de derechos —incluso a nivel interno-.

La Corte no hace invocaciones propiamente ${ }^{124}$ en las opiniones sobre la competencia consultiva de la Corte (OC-1/82, OC-2/82, OC-10/89, y en lo conducente OC-3/83), sobre la competencia de la CIDH (OC-13/ 93, OC-15/97, OC-19/05) y aspectos relativos al procedimiento ante este órgano - cuándo se han de considerar agotados los recursos internos, que es condición de admisibilidad de la petición- (OC-11/90). Tampoco en lo relativo a la interpretación de varios artículos de la CADH: el ar-

124 En algunas de ellas sí recurre a la comparación con el sistema europeo: Corte IDH, "Otros tratados". Objeto de la función consultiva de la Corte, cit., nota 5; Corte IDH, Restricciones a la pena de muerte, cit., nota 5; Corte IDH, Ciertas atribuciones de la Comisión Interamericana de Derechos Humanos; Corte IDH, Informes de la Comisión Interamericana de Derechos Humanos, cit., nota 23. 
tículo 4o., párrafos 20. y 4o., relativo a las restricciones de la pena de muerte (OC-3/83); los artículos 7o. párrafo 6o.; 25 párrafo 1o., y 27 párrafo 2o., con el fin de determinar si es posible suspender el derecho al recurso de habeas corpus en los estados de emergencia (OC-8/87); y los artículos 8o., 25 y 27, párrafo 2o., para precisar cuáles son las garantías judiciales indispensables no susceptibles de suspensión en los estados de emergencia (OC-9/87). Todos son temas que se refieren a aspectos muy puntuales de la letra de la CADH y del funcionamiento del sistema interamericano.

\section{CONCLUSIÓN ${ }^{125}$}

1. Ya desde la primera opinión consultiva, el sistema europeo fue punto de referencia para la Corte IDH. De 19 opiniones consultivas, sólo seis no hacen mención de ese sistema. Pero en lo que se refiere específicamente a la jurisprudencia del TEDH, sólo ocho opiniones consultivas hacen invocación expresa.

2. Desde el punto de vista cuantitativo, sobresale la opinión sobre la condición jurídica y derechos del niño (OC-17/02). Pero cualitativamente, son relevantes esa misma y la relativa a la condición jurídica y derechos de los migrantes indocumentados (OC-18/03). En esta última se precisa aún más el alcance del principio de no discriminación, los límites de los órganos internacionales de protección de los derechos humanos y la eficacia de la CADH. Aunque, naturalmente, no se ha de soslayar la importancia de la opinión sobre el derecho a la información sobre la asistencia consular en el marco de las garantías del debido proceso legal (OC-16/99), porque señala un criterio hermenéutico, que podría tener especial repercusión.

Sobre el derecho a la libertad de expresión, desarrollado de modo particular en la opinión sobre la colegiatura obligatoria de los periodistas (OC-5/85), lo interesante es que la Corte, previo a la recepción de la jurisprudencia europea, realiza una homologación de los artículos 10 del CEDH y 13 de la CADH. Tal homologación la hace para señalar que la democracia constituye el marco para la determinación de las restricciones válidas de ese derecho. Se muestra así el peso de la labor

125 No se hacen conclusiones sobre el marco conceptual, porque su desarrollo tuvo sólo carácter instrumental. 
hermenéutica de la Corte que hace posible la invocación de una jurisprudencia que emerge en un contexto normativo significativamente diferente.

3. Aunque el mayor número de sentencias invocadas se ha dado en las últimas opiniones consultivas, parece que acudir a la jurisprudencia del TEDH ha estado más determinado por el tema - la materia sobre la que versa la opinión - que por los otros factores analizados. Sin embargo, es patente que la integración del órgano y la época de la resolución - considerando en esto también el momento histórico institucional del sistema europeo - tienen su cuota de incidencia.

4. En todo caso, lo que se puede constatar es que la influencia del TEDH trasciende las fronteras del sistema regional europeo, a tal grado que se puede decir que su jurisprudencia constituye una fuente material de destacada relevancia en el ámbito americano, pues al incorporarse a la jurisprudencia de la Corte IDH, configura formalmente los ordenamientos jurídicos de este continente. Se está entonces ante un fenómeno de la globalización jurídica que, probablemente, será cada vez más acusado, también porque es de esperar que la Corte IDH comience a conocer un número mayor de temas que ya han sido tratados en el TEDH.

5. Como se advirtió desde el principio, estas líneas han sido casi en su totalidad de naturaleza descriptiva y han arrojado conclusiones muy puntuales sobre la existencia, el grado y las materias de esa influencia, pero ayudan a despertar el interés sobre este fenómeno y pueden servir de plataforma para futuros estudios sobre aspectos más cualitativos: la importancia y repercusiones de esa influencia, la pertinencia de las diversas sentencias invocadas, la determinación de si éstas son muestra de líneas jurisprudenciales consolidadas, etcétera. Esto último llevaría a precisar si algunas de las sentencias del TEDH citadas en la jurisprudencia interamericana no son sino hitos aislados, pero que por haber sido incorporadas en esas opiniones consultivas, sus criterios han quedado como petrificados y con "efectos innegables"126 en el ámbito americano.

126 Corte IDH, Informes de la Comisión Interamericana de Derechos Humanos, cit., nota 23 , párrafo 26 . 


\section{BIBLIOGRAFÍA}

ARRIAGA, Inés y ZOCO, Cristina, "La reforma del sistema de protección de los derechos del hombre instaurado por el convenio europeo de 1950: el protocolo núm. 11", Humana Iura, Suplemento de Derechos Humanos de la Revista Persona y Derecho, Pamplona, núm. 5, 1995.

Albanese, Susana, Derechos Humanos. Estudio de Casos y Opiniones Consultivas, s. 1. i. [Buenos Aires], Editorial de Belgrano, 1997, t. I.

BAZÁN, Víctor, "Amicus curiae, transparencia del debate judicial y debido proceso", Anuario de Derecho Constitucional Latinoamericano, Montevideo, vol. 1, 2004.

BuERGENTHAL, Thomas, Derechos humanos internacionales, 2a. ed., México, Ediciones Gernika, 2002.

__ "Las convenciones Europea y Americana: algunas similitudes y diferencias", Seminario regional referente a la Convención Americana sobre Derechos Humanos organizado por la Comisión Interamericana de Abogados y la Facultad de Derecho de la Universidad de Costa Rica, Washington, Comisión Interamericana de Derechos Humanos-Secretaría General de la OEA, 1980.

CANÇADO TRINDADE, Antonio Augusto, "El nuevo Reglamento de la Corte Interamericana de Derechos Humanos (2000): la emancipación del ser humano como sujeto del derecho internacional de los derechos humanos", Revista IIDH, San José, vol. 30-31, 2001.

DUNSHEE DE ARRANCHES, Carlos Alberto, "La Corte Interamericana de Derechos Humanos", Seminario regional, referente a la Convención Americana sobre Derechos Humanos organizado por la Comisión Interamericana de Abogados y la Facultad de Derecho de la Universidad de Costa Rica, Washington, Comisión Interamericana de Derechos Humanos-Secretaría General de la OEA, 1980.

ESPINAL IRIAS, Rigoberto, "Competencia y funciones de la Corte Interamericana de Derechos Humanos", en NiETO NAvíA, Rafael (ed.), La Corte y el Sistema Interamericano de Derechos Humanos, San José, Instituto Interamericano de Derechos Humanos, 1994.

FAÚNDEZ LEDESMA, Héctor, El sistema interamericano de protección de los derechos humanos. Aspectos institucionales y procesales, 3a. ed., San José, Instituto Interamericano de Derechos Humanos, 2004. 
FIX-ZAMUDIO, Héctor, "Notas sobre el sistema interamericano de derechos humanos", La justicia constitucional iberoamericana, Madrid, Dykinson, 1997.

GARCÍA BAUER, Carlos, "La observancia de los derechos humanos y la estructuración del sistema internacional de protección en el ámbito americano", Seminario regional referente a la Convención Americana sobre Derechos Humanos organizado por la Comisión Interamericana de Abogados y la Facultad de Derecho de la Universidad de Costa Rica, Washington, Comisión Interamericana de Derechos Humanos-Secretaría General de la OEA, 1980.

GARCÍA RAMíREZ, Sergio, "La protección de derechos y libertades en el sistema jurisdiccional interamericano. El amparo interamericano", en FIX-ZAMUDIO, Héctor y FERRER MAC-GREGOR, Eduardo (eds.), El derecho de amparo en el mundo, México, UNAM-Porrúa-Konrad Adenauer Stiftung, 2006.

GIALDINO, Rolando E., "La Corte Interamericana de Derechos Humanos y sus reglamentos", Anuario Latinoamericano de Derecho Constitucional, Montevideo, vol. 2, 2006.

GROS ESPIELL, Héctor, "El procedimiento contencioso ante la Corte Interamericana de Derechos Humanos", La Corte Interamericana de Derechos Humanos. Estudios y documentos, San José, Instituto Interamericano de Derechos Humanos, 1985.

— Estudios sobre derechos humanos, Madrid, IIDH-Civitas, 1988.

—_ La Convención Americana de Derechos Humanos y la Convención Europea de Derechos Humanos. Análisis comparativo, Santiago, Editorial Jurídica de Chile, 1991.

INSTITUTO INTERAMERICANO DE DERECHOS HUMANOS, Guía metodológica para el desarrollo de un curso sobre el sistema interamericano de derechos humanos, San José, IIDH-McCormick Tribune Foundation, 2002.

LONDOÑO LÁZARO, María Carmelina, "Las cortes Interamericana y Europea de Derechos Humanos en perspectiva comparada", International Law-Revista Colombiana de Derecho Internacional, Bogotá, núm. 5, junio de 2005, http://www.javeriana.edu.co/juridicas/pub_rev/internatio nal_law/revista_5/3.pdf

MOYER, Charles, "The Role of Amicus Curiae in the Inter-American Court of Human Rights", La Corte Interamericana de Derechos Humanos. 
Estudios y Documentos, San José, Instituto Interamericano de Derechos Humanos, 1985.

NIKKEN, Pedro, "La función consultiva de la Corte Interamericana de Derechos Humanos", Memoria del Seminario: El sistema interamericano de protección de los derechos humanos en el umbral del silgo XXI, San José, Corte IDH, 2003, t. I.

PACHECO GÓMEZ, Máximo, "La competencia consultiva de la Corte Interamericana de Derechos Humanos", Memoria del Seminario: El sistema interamericano de protección de los derechos humanos en el umbral del siglo XXI, San José, Corte IDH, 2003, t. I.

RODRÍGUEZ RESCIA, Víctor Manuel, "Eficacia de la jurisprudencia de la Corte Interamericana de Derechos Humanos", en NIETO NAVÍA, Rafael (ed.), La Corte y el sistema interamericano de derechos humanos, San José, Instituto Interamericano de Derechos Humanos, 1994.

RUIZ MiguEL, Carlos, "La función consultiva en el sistema interamericano de derechos humanos, ¿crisálida de una jurisdicción supra-constitucional?", Liber amicorum: Héctor Fix Zamudio, San José, Corte IDH, 1998, vol. II.

ÚBEDA DE TORRES, Amaya, Estudio comparado de los sistemas europeo e interamericano de protección de los derechos humanos, Madrid, Reus, 2007.

VENTURA RoBLeS, Manuel, "La Corte Interamericana de Derechos Humanos: camino hacia un Tribunal permanente", Corte Interamericana de Derechos Humanos, El futuro de la Corte Interamericana de Derechos Humanos, 2a. ed, San José, Corte IDH-ACNUR, 2003.

_ diata de convertirse en un tribunal permanente", La Corte Interamericana de Derechos Humanos. Un cuarto de siglo: 1979-2004, San José, Corte Interamericana de Derechos Humanos, 2005.

- y ZOVATTO, Daniel, La función consultiva de la Corte Interamericana de Derechos Humanos. Naturaleza y principios, 1982-1987, Madrid, IIDH-Civitas, 1989.

Página electrónica

www.corteidh.or.cr

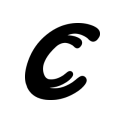

